\title{
Análisis relacional entre elementos de higiene bucal con alteraciones sobre esmalte dental superficial
}

\author{
Relational analysis between elements of oral hygiene \\ with alterations in superficial dental enamel
}

Tatiana Marin Villa ${ }^{1 a}$

Hely Dayana Beltran Pacheco ${ }^{1 a}$

Gloria Emilsen Pabon Ortiz ${ }^{1 b}$

\author{
D https://orcid.org/0000-0002-4666-8036 \\ https://orcid.org/0000-0003-0181-667X \\ https://orcid.org/0000-0003-4281-7249
}

Correspondencia: tmarin2@estudiantes.areandina.edu.co

\section{Resumen}

Objetivo: Relacionar los elementos de higiene bucal más utilizados por los pacientes de la Clínica Odontológica de la Fundación Universitaria del Área Andina con alteraciones sobre el esmalte dental superficial durante el periodo 2019-3 y 2020-3. Métodos: El estudio utilizó un diseño descriptivo transversal retrospectivo. Tuvo como enfoque el método cuantitativo. Se seleccionó, como población objeto, pacientes entre 18 y 65 años que asisten a la clínica, de los cuáles se tomó como referentes sus historias clínicas; la muestra se realizó por medio del programa Netquest. El tamaño de la muestra fue de 116 historias clínicas con un formulario de Google en el que se registraron los datos correspondientes de cada paciente, acerca de los elementos utilizados en la higiene bucal y si ha presentado alteraciones sobre el esmalte dental superficial. Posteriormente se realizó el análisis estadístico con el programa IBM SPSS. Resultados: Se obtuvo que el $98.3 \%$ utiliza cepillo dental, el $96.6 \%$ utiliza crema dental, el $65.5 \%$ utiliza seda dental, el $42.2 \%$ utiliza enjuague bucal, el $12.1 \%$ utiliza palillos, el $17.2 \%$ utiliza bicarbonato de sodio, el $0.9 \%$ utiliza carbón/ceniza y el $0.9 \%$ utiliza hierbas para asear su boca. Entre las alteraciones del esmalte dental superficial se encuentra que el $80.2 \%$ de las personas no presenta alteraciones, el $6.9 \%$ presenta atrición dental, el $6 \%$ presenta abrasión dental, el otro $6 \%$ presenta abfracción dental. Conclusión: No hay relación directamente proporcional entre estos elementos de los pacientes con las alteraciones del esmalte dental superficial.

Palabras clave: higiene bucal, esmalte dental, salud bucal

\begin{abstract}
Objective: To relate the oral hygiene elements most used with the alterations in the superficial dental enamel in patients of the dental clinic of the Fundación Universitaria del Área Andina during the period 2019-3 and 2020-3. Methods: A retrospective cross-sectional descriptive design a quantitative approach were used. The population consisted of patients aged 18 to 65 years who attended the dental consultation. The clinical records of the patients were taken as references. The sample consisted of 116 medical records and was obtained through the Netquest program. To record the corresponding data for each patient, such as the elements used in oral hygiene and the alterations that occur in superficial tooth enamel, a Google form was used. Subsequently, the statistical analysis was carried out with the IBM SPSS program. Results: It was found that $98.3 \%$ use a toothbrush, $96.6 \%$ use toothpaste, $65.5 \%$ use dental floss, $42.2 \%$ use mouthwash, $12.1 \%$ used toothpicks, $17.2 \%$ use sodium bicarbonate, $0.9 \%$ use charcoal/ash and $0.9 \%$ use herbs to clean their mouth. Among the alterations of the superficial dental enamel it was found that $80.2 \%$ of the people do not present alterations, $6.9 \%$ present dental attrition, $6 \%$ present dental abrasion, and the other $6 \%$ present dental abfraction. Conclusion: There is no directly proportional relationship between these elements and the alterations of the superficial dental enamel in patients.
\end{abstract}

Keywords: oral hygiene, dental enamel, oral health

\footnotetext{
${ }^{1}$ Fundación Universitaria del Área Andina. Bogotá, Colombia

a Estudiante

${ }^{\mathrm{b}}$ Docente Universitaria. Rehabilitador Oral
} 


\section{Introducción}

Según la Organización Mundial de la Salud (OMS), ${ }^{1}$ la salud bucodental es un factor esencial para disfrutar de una buena salud y una excelente calidad de vida. Se puede precisar como la ausencia de dolor orofacial, cáncer de boca o de garganta, infecciones y llagas bucales, enfermedades periodontales (de las encías), caries, pérdida de dientes y otras enfermedades y trastornos que fijan en la persona afectada la capacidad de realizar diferentes actividades como la de morder, masticar, sonreír y hablar, al tiempo que implican en su bienestar psicosocial.

Según el informe de la Secretaría de Salud de Bogotá, ${ }^{2}$ la prevención específica en odontología tiene un elemento común: el control de la placa bacteriana mediante una adecuada higiene bucal; teniendo en cuenta que la supresión de la actividad microbiana ha demostrado ser eficaz en la prevención del desarrollo de lesiones cariosas y pérdidas de inserción periodontal.

Los profesionales en el área de la salud recomiendan utilizar 3 elementos indispensables para tener una higiene bucal aceptable: cepillo dental, seda dental y colutorios; sin embargo, en nuestra práctica clínica, nos encontramos, con frecuencia, con algunos pacientes que utilizan implementos extras para la higiene en la cavidad bucal, los mismos que repercuten al presentar alteraciones en la superficie del esmalte dental.

Además, dentro de la alimentación diaria de las personas se ha observado que las bebidas carbonatadas ocasionan un efecto erosivo a raíz del pH y por la regulación de su contenido ácido, teniendo presente que hay diversidad de alimentos que contienen dosis pequeñas de bicarbonato de sodio, flúor, fosfato y calcio, que contribuyen de una manera abrasiva al deterioro en la superficie del esmalte dental superficial.

El descuido de la higiene dental trae como consecuencia inmediata la placa bacteriana, la cual la definen Marsh y Martin ${ }^{3}$ como una compleja comunidad microbiana que se encuentra en la superficie de los dientes, enfrascada en una matriz de origen bacteriano y salival. Dentro de esta placa es posible encontrar hasta más de 300 especies bacterianas que, si favorecemos su propagación, pueden ocasionar diversas enfermedades y alteraciones dentales; cuya remoción se realiza, en primera instancia, con el cepillado, que la elimina por arrastre o fricción. Para que este proceso tenga éxito se complementa la rutina con seda dental y colutorios. ${ }^{4,5}$

Por lo tanto, para la prevención de este tipo de enfermedades, los profesionales en el área de la salud recomiendan utilizar los elementos de higiene bucal como el cepillo, seda y pasta dental, colutorios, bicarbonato de sodio, hierbas, palillo, carbón / ceniza, entre otros; que, de cierta manera, también inciden en las alteraciones del esmalte dental superficial por su mal uso.

El mecanismo abrasivo generado por un cepillado exagerado y vigoroso, cepillado abusivo, traumático, o neurótico tiene una extensa data en la bibliografía del área, remontándose a los estudios in vitro de Miller, quien señalaba el potencial abrasivo de cepillos, cremas y polvos. La relación se hizo primariamente con el cepillado horizontal; sin embargo, otros autores señalaron al cepillado rotativo o vertical como más dañinos, siendo que la abrasividad de las pastas dentales influye decisivamente. Hay múltiples factores a tomar en cuenta, siendo fundamentales: el tiempo requerido para realizar la higiene, la frecuencia diaria, la presión ejercida e incluso el lugar de inicio. ${ }^{6}$

Una de las alteraciones más frecuentes en el esmalte dental es la erosión dental, que se describe en odontología como el resultado físico de una pérdida dental patológica, indolora, crónica y localizada de los tejidos dentales por acción química de quelantes o ácidos; no están asociados a los producidos por la microbiota bacteriana que ocasiona la caries dental o por factores traumáticos o mecánicos. También se 
puede decir que las bebidas carbonatadas y no carbonatadas causan una significativa erosión del esmalte a largo plazo; además, repercuten sobre la salud bucal con la pérdida de tejido que produce sensibilidad y por ende una apariencia poco estética. ${ }^{7}$

La pérdida de sustancia, o desgaste dental, es conocida como un problema en salud bucal, tanto en niños como en adultos, la cual puede suceder de diferentes formas, como abrasión, atrición, abfracción, erosión dental. De cierta manera tienen incidencias en la higiene bucal de la persona, y es por tal razón que se ha llegado, incluso, a determinar que tienen que ver con un uso inadecuado de los elementos de higiene dental que se han venido mencionando.

Por tanto, es importante comprender que esta situación requiere ser estudiada a profundidad y sobre una comunidad en específico para poder definir si realmente existe una relación entre el uso de los elementos de higiene dental o, en su defecto, no hay un nexo causal entre ellas que permita asociarlas, de cierta forma, entre sí.

De conformidad con lo anterior, resultó pertinente determinar si estos elementos de higiene bucal tienen influencia directa en las alteraciones del esmalte dental superficial; por tanto, dentro del presente artículo, se demostrará los resultados de un análisis relacional de estos elementos con las alteraciones estudiadas para poder determinar si existe un nexo entre ellas.

Cabe destacar que la pregunta a responder, previa a la realización del artículo, es la siguiente ¿De qué forma se pueden relacionar los elementos de higiene bucal más utilizados por los pacientes de la Clínica Odontológica de la Fundación Universitaria del Área Andina relacionados con las alteraciones sobre el esmalte dental superficial durante el periodo $2019-3$ y 2020-3?

\section{Materiales y métodos}

La investigación tiene un diseño descriptivo transversal retrospectivo, cuya finalidad es la descripción, dado que los datos utilizados son expuestos de esa manera. Es transversal debido a que examina la relación entre los elementos de higiene bucal y las alteraciones sobre el esmalte dental superficial; asimismo es retrospectivo debido a que el diseño es posterior a los hechos que se estudian y los datos se obtienen de archivos y de los sujetos que se refieren.

Los criterios de inclusión fueron los siguientes: 1) Historias clínicas con consentimiento informado, debidamente diligenciado; 2) pacientes entre los 18 y 65 años; 3) pacientes dentados o parcialmente dentados; 4) ambos sexos. Se excluyeron a los pacientes menores de edad y a los pacientes con prótesis total.

El enfoque de la presente investigación es de carácter cuantitativo, toda vez que el área de estudio será la comunidad de pacientes señalada, buscando determinar si estos han tenido alteraciones en el esmalte dental superficial en causalidad con los elementos de higiene bucal.

Por tanto, el método utilizado fue el deductivo, toda vez que a partir de los resultados cuantitativos que serán recolectados se deducirá si existe o no la relación planteada dentro del acápite introductorio.

La muestra escogida son todas las historias clínicas presentes y activas en la clínica en cuestión, omitiendo las historias clínicas pediátricas; dando como resultado un total de 278 historias clínicas. La muestra se realizó por medio del programa Netquest con una heterogeneidad del $50 \%$, un margen de error del $7 \%$ y 
un nivel de confianza de $95 \%$; de donde se obtuvo, como tamaño de muestra, 116 historias clínicas en el periodo indicado.

De este modo, los instrumentos de recolección de información fueron las historias clínicas sustentadas y firmadas y una lista de chequeo con respecto al IV Estudio Nacional de Salud Bucal (ENSAB IV). ${ }^{8}$

\section{Figura 1}

Recolección de información sobre uso de elementos de higiene bucal

\begin{tabular}{|c|c|c|c|}
\hline \multirow{10}{*}{220} & \multirow{10}{*}{$\begin{array}{l}\text { ¿Qué utiliza usted para asear su boca? } \\
\text { Espere respuesta, puede marcar varias opciones }\end{array}$} & a) Cepillo & \\
\hline & & b) Crema dental & \\
\hline & & c) Seda dental & \\
\hline & & d) Enjuague bucal & \\
\hline & & e) Palillos & \\
\hline & & f) Bicarbonato & \\
\hline & & g) Carbón / Ceniza & \\
\hline & & h) Sal & L \\
\hline & & i) Hierbas & \\
\hline & & j) Otro ¿Cuál? & \\
\hline
\end{tabular}

Nota: Imagen tomada del Anexo 4, instrumentos del ENSAB IV. Módulo 2. II Modos de vida y salud bucal. Tabla 220

Con respecto a las historias clínicas, se llevó a cabo un formulario de Google registrando los datos correspondientes de cada paciente, acerca de los elementos utilizados en la higiene bucal y si ha presentado alteraciones sobre el esmalte dental superficial.

Para la realización y obtención de cada uno de los datos se tuvo en cuenta "Modos de Vida" de la encuesta del ENSAB IV, anexado en las historias clínicas de la Fundación Odontológica del Área Andina; las cuales también contaban con un consentimiento informado, el cual dejaba en claro que las historias clínicas se podrían usar para fines académicos. Las historias clínicas que no tenían ese consentimiento informado o que no estuviesen firmadas, no fueron utilizadas.

Para el análisis estadístico descriptivo se utilizaron tablas de frecuencia con el programa estadístico IBM SPSS. 


\section{Resultados}

Los resultados obtenidos en esta investigación, a partir de las encuestas realizadas en Google, tal y como se visibiliza en los gráficos, fueron como sigue.

Se obtuvo como resultado en general que el $98.3 \%$ utiliza cepillo dental, el $96.6 \%$ utiliza crema dental, el $65.5 \%$ utiliza seda dental, el $42.2 \%$ utiliza enjuague bucal, el $12.1 \%$ utiliza palillos, el $17.2 \%$ utiliza bicarbonato de sodio, el $0.9 \%$ utiliza carbón/ceniza y el $0.9 \%$ utiliza hierbas para asear su boca (Figura 2).

\section{Figura 2}

Registro de los elementos de higiene bucal más utilizados en los periodos 2019-3 y 2020-3

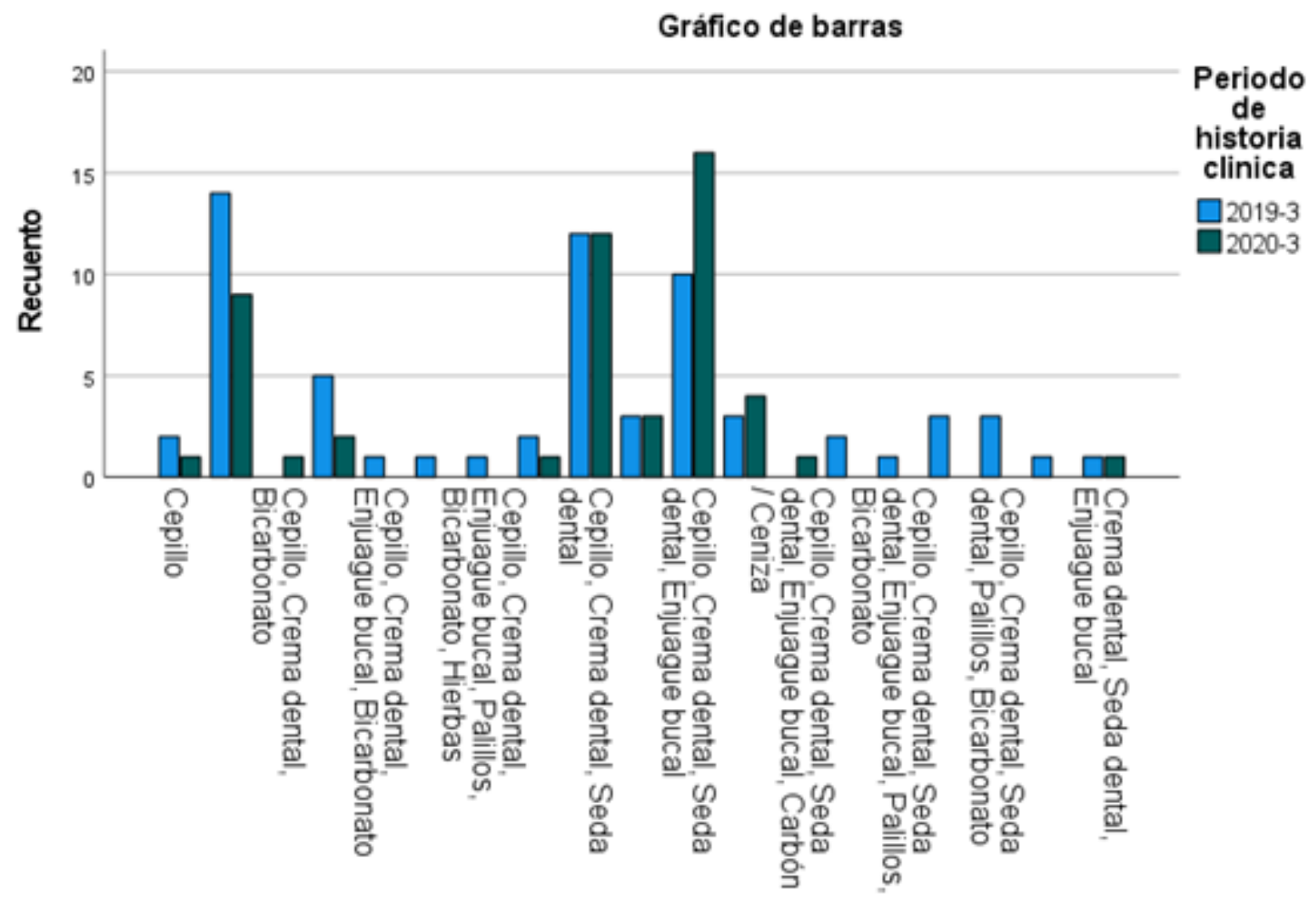

De las historias clínicas también se obtuvo que el $74.14 \%$ de los pacientes no presentaban alteraciones sobre el esmalte dental superficial; el $6.90 \%$, tal vez sí presentaba alteraciones y el $18.97 \%$ presentaban alteraciones en el esmalte dental (Figura 3). 


\section{Figura 3}

Presenta alteraciones sobre el esmalte dental superficial

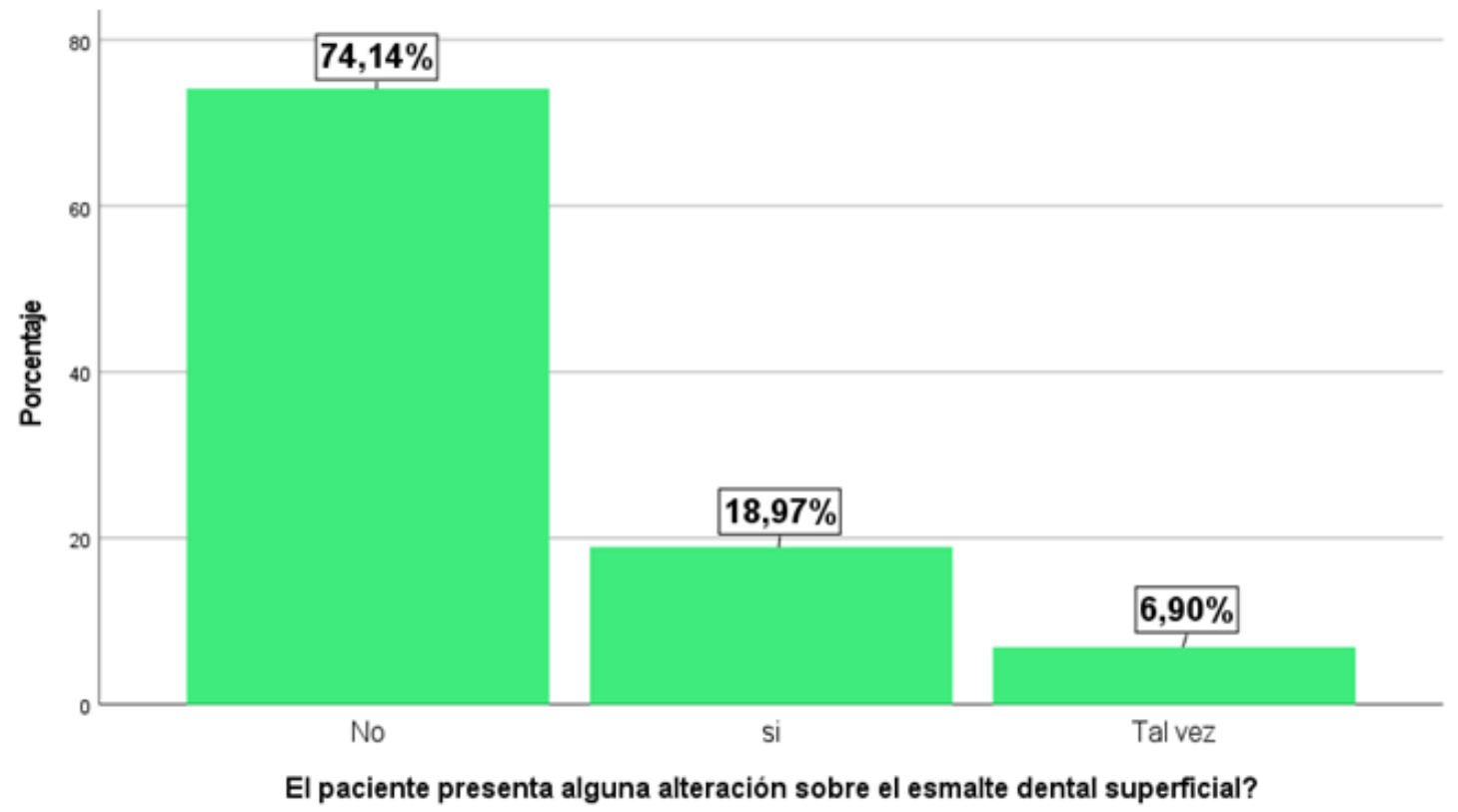

Entre las alteraciones del esmalte dental superficial se encuentra que el $81.03 \%$ de las personas no presenta alteraciones, el $6.90 \%$ presenta atrición dental, el $6.03 \%$ presenta abrasión dental, el otro $6.03 \%$ presenta abfracción dental. Ningún paciente presentó hipoplasia dental ni erosión dental (Figura 4).

\section{Figura 4}

Tipo de alteraciones que presentan los pacientes sobre el esmalte dental superficial

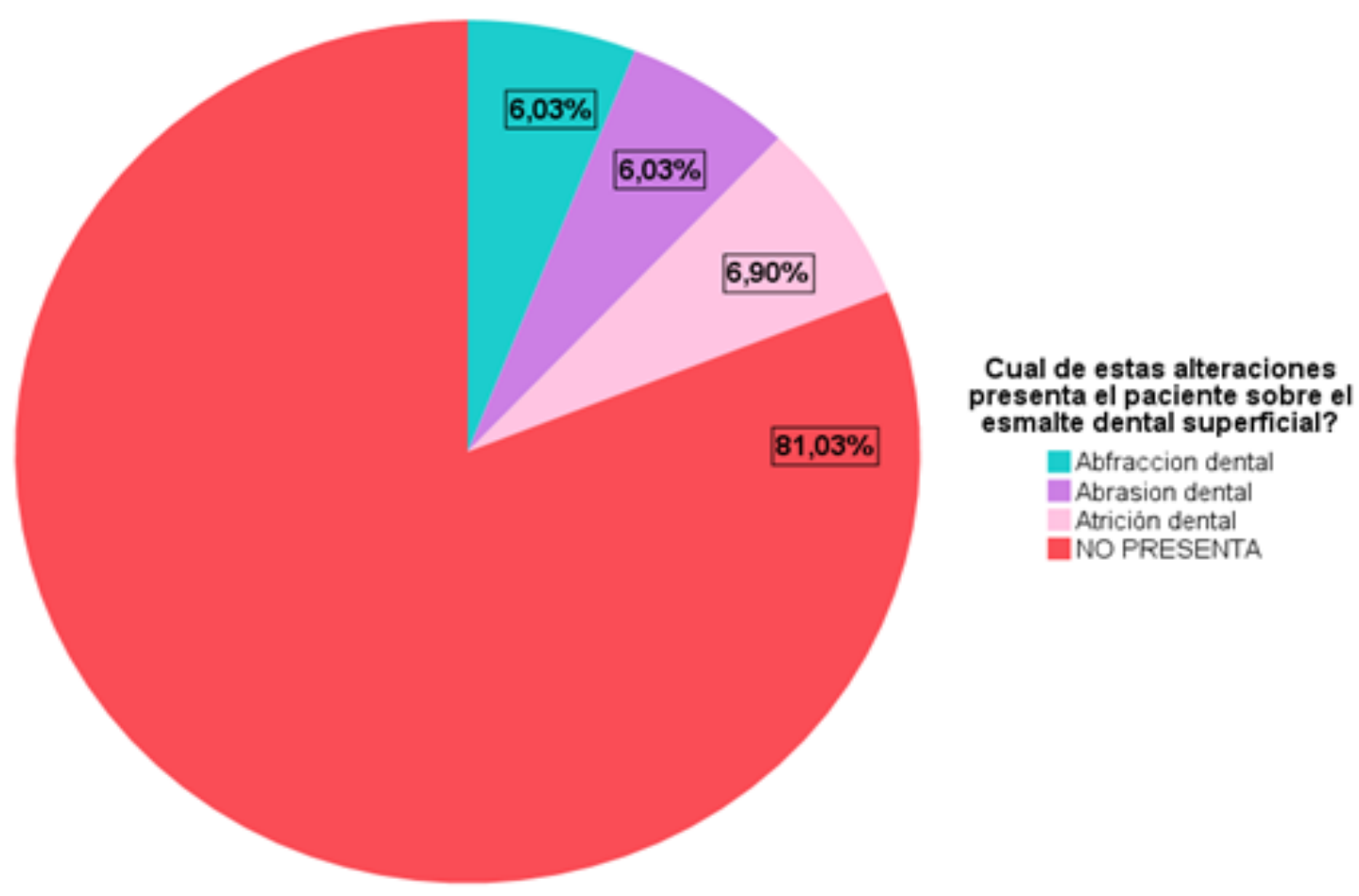


En el periodo del 2019-3 el porcentaje de historias clínicas evaluadas en los pacientes de nuestra investigación es del $56 \%$, que equivale a 65 historias clínicas, y en el periodo del 2020-3 el porcentaje de historias clínicas evaluadas es del $44 \%$, que equivale a 51 (Tabla 1).

\section{Tabla 1}

Análisis de los periodos 2019-3 y 2020-3 respecto si se presentan alteraciones sobre el esmalte dental superficial

\begin{tabular}{l|l|l|l|r|r}
\cline { 2 - 5 } & & No & si & Tal vez & Total \\
\hline $\begin{array}{l}\text { Periodo de historia } \\
\text { clinica }\end{array}$ & $2019-3$ & $\mathbf{5 1}$ & $\mathbf{1 0}$ & $\mathbf{4}$ & 65 \\
\hline Total & $2020-3$ & $\mathbf{3 5}$ & $\mathbf{1 2}$ & $\mathbf{4}$ & 51 \\
\hline
\end{tabular}

Del periodo 2019-3 se registraron 40 personas de género femenino; de las cuales, 7 presentaron alteraciones en el esmalte dental superficial; 32, no presentaron lesiones; y 1, tal vez. Del periodo 2020-3 se registraron 34 personas de género femenino; de las cuales, 7 presentaron alteraciones en el esmalte dental superficial; 24 , no presentaron lesiones; y 3 , tal vez.

Del periodo 2019 -3 se registraron 25 personas de género masculino; de las cuales, 3 presentaron alteraciones en el esmalte dental superficial; 19, no presentaron lesiones; y 3, tal vez. Del periodo 2020-3 se registraron 17 personas de género masculino; de las cuales, 5 presentaron alteraciones en el esmalte dental superficial, 11 no presentaron lesiones y 1 , tal vez (Tabla 2 ).

\section{Tabla 2}

Análisis de los periodos 2019-3 y 2020-3 con respecto al género

\begin{tabular}{|llrrrr|}
$\begin{array}{l}\text { Cuenta de Periodo de historia clinica } \\
\text { Etiquetas de fila }\end{array}$ & $\begin{array}{c}\text { Etiquetas de columna } \\
\text { No }\end{array}$ & \multicolumn{2}{c}{ si } & \multicolumn{3}{c|}{ Tal vez } & \multicolumn{2}{c|}{ Total general } \\
\hline $\mathbf{2 0 1 9 - 3}$ & & $\mathbf{5 1}$ & $\mathbf{1 0}$ & $\mathbf{4}$ & $\mathbf{6 5}$ \\
\hline Femenino & 32 & 7 & 1 & 40 \\
Masculino & 19 & 3 & 3 & 25 \\
$\mathbf{2 0 2 0 - 3}$ & & $\mathbf{3 5}$ & $\mathbf{1 2}$ & $\mathbf{4}$ & $\mathbf{5 1}$ \\
\hline Femenino & 24 & 7 & 3 & 34 \\
Masculino & 11 & 5 & 1 & 17 \\
\hline Total general & $\mathbf{8 6}$ & $\mathbf{2 2}$ & $\mathbf{8}$ & $\mathbf{1 1 6}$ \\
\hline
\end{tabular}

\section{Discusión}

De los resultados emitidos dentro del acápite anterior se puede apreciar, claramente, que las personas, principalmente, utilizan dentro de su higiene bucal cotidiana el cepillo y la crema dental, siendo en un gran porcentaje, por no decir la mayoría, los elementos principales para una correcta higiene bucal.

Lo anteriormente expuesto es un resultado claro, debido a que en el transcurso de los años han sido los principales elementos de la higiene bucal. Como indica Báscones, ${ }^{9}$ han sido, a lo largo de la historia moderna, los instrumentos más relevantes al momento de realizarse la higiene bucal diaria por parte de la sociedad.

Tal y como lo expresan Rizzo-Rubio et al., ${ }^{10-12}$ se recomienda, entre los diferentes métodos para la higiene bucal, el cepillado, el uso de la seda (que toma fuerza actualmente), el concepto de la importancia de los dentífricos, así como se entiende que el esmalte es un tejido vivo y dinámico, lo cual puede incorporar minerales provenientes del fluido bucal. 
Por otro lado, se encuentra, además, que menos de la mitad de la población utiliza enjuague bucal, lo que permite comprender que las personas no tienen claridad o el pleno conocimiento de lo que significa el enjuague para la higiene bucal; que de acuerdo con Báscones, ${ }^{13}$ quien considera que para una correcta protección dental es necesario que se aplique el enjuague bucal dos veces al día, siendo una prevención contra las bacterias y demás enfermedades dentales que pueden aparecer y que, en la actualidad, son muy frecuentes.

Y es así como también se refleja en las historias clínicas que se expusieron como resultados, en donde la gran mayoría de personas no presentan alteraciones en el esmalte dental superficial; sin embargo, esto no indica que no sea un tema de preocupación para los profesionales de la odontología, dando lugar a que se estudien las principales causas de estas alteraciones sobre cierta parte de la población.

Examinando esto, Da Costa Dutra ${ }^{14}$ cita, en su artículo, que, además del cepillado excesivo y la mala técnica, ha sido reportado que la utilización indebida de instrumentos de higiene bucal, hábitos profesionales y aparatos ortodóncicos, pueden provocar lesiones de abrasión por la fricción de estos objetos con la estructura dentaria o probablemente por direccionamiento de fuerzas excéntricas para algún área del diente, debido al esfuerzo masticatorio, promoviendo el desgaste. ${ }^{15-17}$

De igual manera, diversos autores al estudiar las posibles causas de las alteraciones del esmalte dental no mencionan, entre las que puedan darse, la utilización de los elementos de higiene bucal, como es el caso de González, ${ }^{18}$ quien señala que esta patología oral puede darse por factores genéticos, hereditarios o de descuido en el cuidado bucal, no haciendo referencia alguna a los elementos ya mencionados.

Por el contrario, en su estudio, Díaz, R.O.E. et al. ${ }^{19}$ refirieron que, bajo el microscopio, una superficie abrasionada suele presentar arañazos orientados al azar, numerosas picaduras y diferentes marcas. La distribución y la extensión de desgaste abrasivo sobre la superficie dependen de muchas variables, como el tipo de oclusión, la dieta, el estilo de vida, la edad y la higiene oral. Así mismo, se puede encontrar que algunos elementos de higiene mal utilizados pueden ocasionar diversos daños a nivel de la cavidad bucal, como lo expresan Baracaldo Ortíz et al ${ }^{20}$ señalando que, aunque todavía no exista un cepillo de dientes ideal, no se recomienda uno con cerdas duras, ya que puede contribuir a un daño periodontal por causa de trauma en la encía, que puede producir recesiones de la misma. Lo más indicado es un cepillo que tenga cerdas suaves o blandas, con extremos redondeados y de material sintético ya que sus filamentos son más homogéneos y tienen mejor elasticidad, mejor resistencia a romperse y son hidrofóbicos.

Trancho (s.f.), ${ }^{21}$ por su parte, considera, principalmente, que las alteraciones del esmalte dental se pueden dar por la aparición de infecciones bucales como las caries, enfermedades periodontales; que de cierta manera responden a una inadecuada higiene por parte de la persona que sufre la patología.

De conformidad con lo anterior, es claro que, desde el punto de vista académico, en relación con el factor práctico y cuantitativo, se analizaron y se dieron los resultados dentro del presente artículo, permitiendo determinar que los elementos de higiene bucal y su utilización no tienen una relación directamente proporcional a las alteraciones del esmalte dental, que por el contrario, podría afirmarse que el uso de estos elementos utilizados adecuadamente, de cierta manera, pueden prevenir la aparición de la patología oral descrita, siendo una contribución para las personas el mantener su salud bucal en condiciones adecuadas, estando al pendiente y al cuidado de cualquier situación que pueda afectar la higiene y derive en enfermedades dentales.

Es así como también se refleja en las historias clínicas que se expusieron en este estudio, donde la gran 
mayoría de personas no presentan alteraciones en el esmalte dental superficial; sin embargo, esto no indica que no sea un tema de preocupación para los profesionales de la odontología, dando lugar a que se estudien las principales causas de estas alteraciones sobre cierta parte de la población.

\section{Conclusiones}

La investigación que se realizó, a partir del planteamiento del problema del presente artículo, permite delimitar, en primer lugar, que las personas tienen como principales elementos de higiene bucal el cepillo dental, crema dental, seda dental, enjuague bucal y bicarbonato de sodio, que, de cierta manera, han sido comprendidos como los elementos que contribuyen de mejor forma al cuidado bucal.

Así mismo, se pudo determinar que, en el periodo analizado, las alteraciones en el esmalte dental superficial no fueron superiores a 7 casos, no generando un alto índice de alteraciones en los pacientes, especialmente en el género femenino.

De igual manera, haciendo énfasis en la relación de los elementos de higiene bucal que fueron utilizados principalmente por los usuarios con las alteraciones en el esmalte dental superficial, no se visualiza un nexo entre ellas o una relación directamente proporcional, debido a que por el uso de los elementos no hay una causa directa de las alteraciones en el esmalte dental superficial.

Siendo así, se puede concluir entonces que, para el presente estudio realizado, no se puede considerar que los elementos de la higiene bucal inciden directamente en la generación de las alteraciones dentales superficiales; por tanto, resulta pertinente reflexionar acerca de realizar una investigación que permita determinar si estas alteraciones se presentan por otros factores, bien sea por falta de cuidado, de mantenimiento o de la realización de tratamientos estéticos, siendo un tema importante para analizar a profundidad contando con este estudio, el cual contiene un aporte administrativo interno para la comunidad de la Clínica Odontológica de la Fundación Universitaria del Área Andina.

\section{Referencias}

1. Organización Mundial de la Salud. Salud bucodental [Internet] .2021 [cited 11 August 2021]. Available from: https://www.who.int/topics/oral_health/es/

2. Guía de práctica clínica para el diagnóstico, prevención y tratamiento de la caries dental [Internet]. Salud capital. 2007 [cited 11 August 2021]. Available from: http://www.saludcapital.gov.co/DSP/Documentos $\% 20$ Salud\%20Oral/Gu\%C3\%ADa\%20de\%20Pr\%C3\%A1ctica\%20CI\%C3\%ADnica\%20en\%20Salud\%20 Oral\%20-\%20Caries\%20Dental.pdf

3. Marsh P, Martin M. Oral Microbiology. 4ta edition. England: Editorial Elservier,2000.

4. Balanyk T. Estudio clínico comparativo del desempeño de dos cepillos manuales en la remoción de placa. El diario Clínico Odontológico. 1993; (6): 8-12

5. Baracaldo Ortíz YI, Cabuya Cabuya FA, Hurtado Rozo RD, Ricaurte Vila EE, Gamboa Martínez DC, Báez Quintero LC. Evaluación de las técnicas de cepillado de bass y vertical en un grupo de pacientes en tratamiento de ortodoncia con técnica MBT. Acta Odontol. Colomb. [Internet]. 1 de julio de 2012 [citado 11 de agosto de 2021];2(2):33-4. Disponible en: https://revistas.unal.edu.co/index.php/actaodontocol/ article/view/35536

6. Calabria Díaz Hugo F. Lesiones no cariosas del cuello dentario: patología moderna, antigua controversia Odontoestomatología [Internet]. 2009 Mayo [citado 2021 Ago 12] ; 11( 12 ): 12-27. Disponible en: 
http://www.scielo.edu.uy/scielo.php?script=sci_arttext\&pid=S1688-93392009000100003\&lng=es.

7. Clínica Dental Verónica Gil. (2019). Causas y tratamientos de la erosión dental. Disponible en http://www. clinicaveronicagil.com/causas-tratamientos-erosion-dental/

8. Ministerio de Salud. Situación bucal actual. En Salud Md. IV Estudio Nacional de Salud Bucal. Bogotá; 2012. p. 227. disponible en:https://www.minsalud.gov.co/sites/rid/Lists/BibliotecaDigital/RIDE/VS/PP/ ENSAB-IV-Situacion-Bucal-Actual.pdf

9. Fajardo Santacruz Maria Claudia, Mafla Chamorro Ana Cristina. Diagnóstico y epidemiología de erosión dental. Rev. Univ. Ind. Santander. Salud [Internet]. 2011 Aug [cited 2021 Aug 09]; 43(2): 179-189. Available from: http://www.scielo.org.co/scielo.php?script=sci_arttext\&pid=S0121-08072011000200009\&Ing=en.

10. Rizzo-Rubio LM, Torres-CadavidAM, Martínez-Delgado CM. Comparación de diferentes técnicas de cepillado para la higiene bucal. Rev. CES Odont 2016; 29(2): 52-64.

11. Sanabria-Castellanos CM, Suárez-Robles MA, Estrada-Montoya JH. Relación entre determinantes socioeconómicos, cobertura en salud y caries dental en veintepaíses. Rev Gerenc Polít Salud. 2015;14 (28):161-189. http://www.scielo.org.co/pdf/rgps/v14n28/v14n28a12.pdf

12. Gluckstein Caracushansky Linda, Martinez Pabon María Cecilia, Mesa Cadavid Liliana. Efecto del dentrifico colgate total sobre el crecimiento del streptococo mutans. Rev Ces Odontol. 2010;10 (2). http:// revistas.ces.edu.co/index.php/odontologia/article/viewFile/1140/718

13. Bascones A, Morante S. (2006). Antisépticos orales: Revisión de la literatura y perspectiva actual. Avances en Periodoncia. Disponible en: http://scielo.isciii.es/scielo.php?script=sci_arttext\&pid=S169965852006000100004\&Ing=es

14. Da Costa Dutra L.; Guerra Seabra E. J.; de Souza Lucena E. E.; Pinheiro Cavalcanti Lima I.Abrasión dentaria y abfracción: Revisión de literatura Acta Odontológica Venezolana Volumen 53, No. 2, Año 2015. Obtenible en: https://www.actaodontologica.com/ediciones/2015/2/art-14/.

15. Pikdöken L, Akca E, Gürbüzer B, Aydil B, Taşdelen B. Cervical wear and occlusal wear from a periodontal perspective. J Oral Rehabil. 2011 Feb; 38(2):95-100.

16. Grippo JO, Simring M, Coleman TA. Abfraction, abrasion, biocorrosion, and the enigma of noncarious cervical lesions: A 20-Year Perspective. J Esthet Restor Dent. 2012 Feb; 24(1):10-23.

17. Grippo JO, Simring M, Schreiner S.Attrition, abrasion, corrosion and abfraction revisited: a new perspective on toothsurface lesions. J Am Dent Assoc. 2004 Aug; 135(8):1109-18

18. González, M. (2012). Anomalías y displasias dentarias de origen genético - hereditario. Av. Odontoestomatol, Vol. 28, No. 6. Disponible en https://scielo.isciii.es/scielo.php?script=sci_ arttext\&pid=S0213-12852012000600004

19. Díaz, R.O.E., Estrada, E.B.E., Franco, G., Espinoza, P.C.A., González, M.R.A., Badillo, M.E. Lesiones no cariosas: atrición, erosión, abrasión, abfracción, bruxismo. Oral Año 12. Núm. 38. 2011. 742-744

20. Baracaldo Ortíz, Yelitza Ivone, Fredy Alexander Cabuya Cabuya, Rubén Darío Hurtado Rozo, Edwin Emil Ricaurte Vila, Diana Constanza Gamboa Martínez, y Liliana Carolina Báez Quintero. «Evaluación de las técnicas de cepillado de bass y vertical en un grupo de pacientes en tratamiento de ortodoncia con técnica MBT». Acta Odontológica Colombiana 2, no. 2 (julio 1, 2012): 33-43. Accedido agosto 9,2021. https://revistas.unal.edu.co/index.php/actaodontocol/article/view/35536.

21. Trancho, G. (SF). Patología oral: Hipoplasia del esmalte dentario. [Internet]. 2011 [cited 12 August 2021]. Disponible en https://webs.ucm.es/info/aep/boletin/actas/32.pdf

- Conflicto de intereses: La presente investigación no presenta conflicto de intereses entre los investigadores.

- Fuente de financiamiento: La presente investigación fue financiada por los investigadores. 